\title{
Material Protrusion
}

National Cancer Institute

\section{Source}

National Cancer Institute. Material Protrusion. NCI Thesaurus. Code C72891.

Problem associated with undesired physical appearance of device material, specifically when material extends beyond or above device surface. 